\title{
Posterior Fusion for Odontoid Fracture in an Infant
} -Case Report-

\author{
Kazuya Uemura, Akira MATSUmURA*, Shozo Noguchi, \\ Tomoyuki SHIBATA, Masami ITO, Eiki KobAYASHI, \\ Yutaka MAKI, and Tadao NOSE*
}

\author{
Department of Neurosurgery and Tsukuba Neurological Institute, Tsukuba Memorial \\ Hospital, Tsukuba, Ibaraki; *Department of Neurosurgery, Institute of Clinical \\ Medicine, University of Tsukuba, Tsukuba, Ibaraki
}

\begin{abstract}
A 2-year-3-month-old girl presented with a rare displaced odontoid fracture. She was managed nonoperatively by manipulation followed by 3 -month extracorporeal fixation with a halo brace. However, lateral radiography revealed recurrent dislocation at the base of the odontoid process. Magnetic resonance imaging demonstrated a "synchondrotic slip." She therefore underwent posterior wiring with iliac bone grafting to prevent pseudoarthrosis. The odontoid process had fused to the axis at 4 months postoperatively. Surgical management should be considered as a treatment method for pediatric odontoid fracture because of the difficulties in maintaining long-term immobilization and confirming the union.
\end{abstract}

Key words: odontoid fracture, magnetic resonance imaging, infant, synchondrosis, posterior fusion

\section{Introduction}

Odontoid fracture in children is rare, and almost always occurs through the fragile cartilaginous plate at the base of the dens. ${ }^{13)}$ Pediatric cervical fracture is prone to occur in the upper segments $(\mathrm{C} 1-3),{ }^{14)}$ and is less likely to cause spinal cord transection. ${ }^{15)}$ The actual pathology in pediatric odontoid fractures has been described as "synchondrotic slip" or "traumatic disruption of the synchondrosis."15) Hyperflexion of the neck is the most common mechanism of injury in such cases. ${ }^{10)}$

Diagnosis is often difficult because the odontoid process does not fuse with the $\mathrm{C}-2$ body before the age of 3-6 years in the normal child. ${ }^{3)}$ Furthermore, physiological angulation of the odontoid process in children makes a pathological condition even more difficult to identify. ${ }^{8}$ Radiography can show retropharyngeal hematoma as a prevertebral shadow or enlargement of the retropharyngeal space, and this may be useful in making the diagnosis of an odontoid fracture. ${ }^{8,14}$ Lateral midline tomography has also been used. ${ }^{13)}$ However, these diagnostic modalities cannot directly show the cartilaginous plate of the odontoid. Computed tomography (CT) and magnetic resonance (MR) imaging should demonstrate disruption of the synchondrosis, but such findings have not been seen. ${ }^{15)}$ MR imaging can demonstrate soft tissue damage which is not shown by $\mathrm{CT}$ or radiography. The management of pediatric odontoid fracture is controversial, but non-operative therapy is preferred. ${ }^{2,6,14)}$

We describe a 2-year-3-month-old girl who suffered a odontoid fracture in a motor vehicle accident. MR imaging in our patient showed the "synchondrotic slip" between the odontoid process and the body of the axis. We discuss the usefulness of surgical management as an alternative choice of therapy.

Received December 12, 1994; Accepted July 19, 1995

Author's present address: K. Uemura, M.D., Department of Neurosurgery, Institute of Clinical Medicine, University of Tsukuba, Tsukuba, Ibaraki, Japan. 


\section{Case Report}

A 2-year-3-month-old girl was an unrestrained, front seat passenger in a motor vehicle which was involved in a high speed crash. She hit her chest on the dashboard when the car crashed. She was found unconscious and tetraparetic at the crash scene and was transferred to a local hospital. She was intubated in the emergency room because of diminished spontaneous breathing. Cervical radiography revealed an anteriorly dislocated odontoid process (Fig. 1). Closed manipulation achieved good alignment, but the $\mathrm{C}-1$ body and the odontoid process remained completely separated from the C-2 body. A halo brace was applied on the same day. Associated injuries included a fracture of the right clavicle and renal contusion on the right. Her consciousness and tetraparesis improved gradually. Two weeks after the accident, only moderate hemiparesis on the right remained. She was then referred to our clinic for further treatment.

The halo brace was left in place for $\mathbf{3}$ months, after which her muscle weakness had completely resolved. However, cervical radiography demonstrated a recurrent dislocation of the odontoid process (Fig. 2). MR imaging showed slippage of the odontoid process from the body of the axis (Fig. 3).

As non-operative treatment had failed to maintain an acceptable reduction, posterior wiring and fusion with autologous iliac crest was performed. The C-1 lamina was wired to the $\mathrm{C}-2$ spinous process with

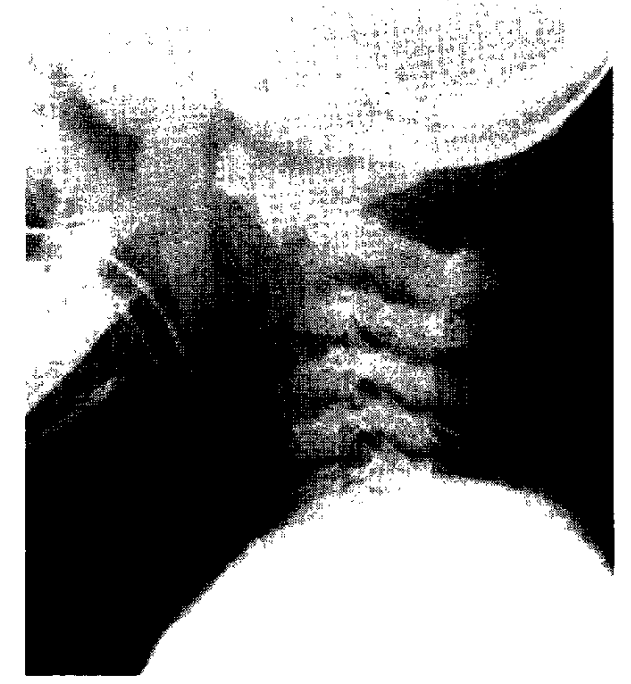

Fig. 1 Lateral cervical radiograph showing the anteriorly displaced odontoid process.

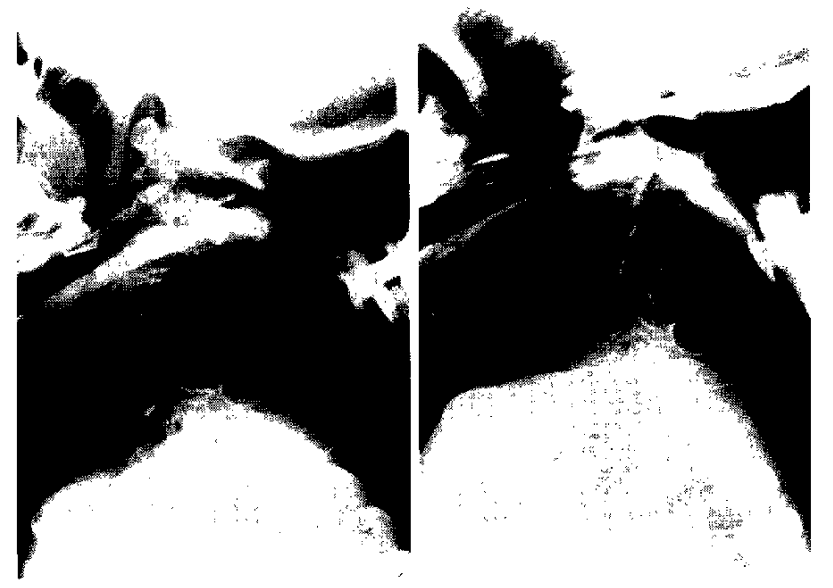

Fig. 2 Lateral cervical radiographs showing the recurrent displacement of the odontoid process, before (left) and after displacement (right).

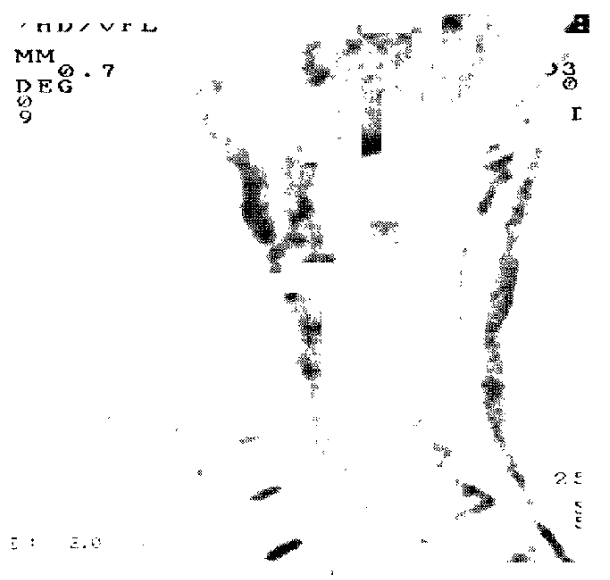

Fig. $3 \mathrm{~T}_{2}$-weighted MR image demonstrating slippage of the odontoid process at the cartilaginous plate on the body of the axis, or "synchondrotic slip."

stainless steel wire. The bone graft was implanted between $\mathrm{C}-1$ and $\mathrm{C}-3$. Four months later, the odontoid process had fused to the body of the axis. However, the bone graft was absorbed (Fig. 4).

\section{Discussion}

Conservative extracorporeal fixation or surgical internal fixation can be used for the management of pediatric odontoid fractures. The preferred method of treatment for pediatric odontoid fractures is nonoperative, ${ }^{2,6,14)}$ because the odontoid process and the body of the axis normally fuse between the ages of 3 


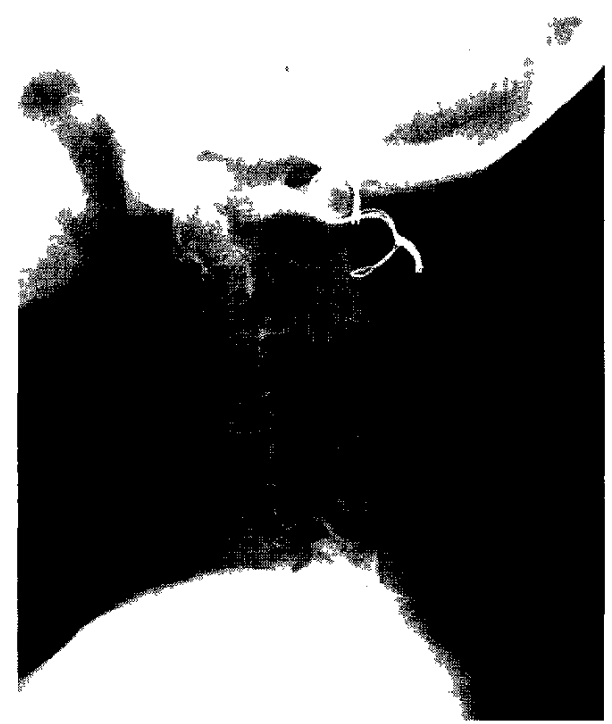

Fig. 4 Lateral cervical radiograph showing the odontoid process united to the body of the axis and absorption of the bone graft 4 months after posterior wiring and fusion.

and 6 years $^{3)}$ and so spontaneous fusion of the synchondrotic separation can be expected. Anderson and D'Alonzo ${ }^{2)}$ found that the prognosis is relatively better in children than in adults with similar injuries because of the different locations of injury. Odontoid fractures in children are different from those in adults, because pediatric odontoid fractures are not true fractures but "slippages" of the cartilaginous plate between the odontoid process and the C-2 body. Ewald ${ }^{8)}$ showed morphologically that the plate between the base of the axis and the odontoid process is cartilaginous, not epiphyseal. The presence of this cartilaginous plate is essential for good healing of the pediatric odontoid fracture. Maintaining an accurate alignment between the odontoid process and the $\mathrm{C}-2$ body is the key to success in the non-operative management scheme, ${ }^{2,5-8,12,14,15)}$ but long-term extracorporeal fixation can be difficult. ${ }^{11)}$ However, surgical treatment can be considered if non-operative therapy fails. Using either therapy, union seldom fails in treated patients under the age of 7 years ${ }^{1,2,4,5,8-11,15)}$ but non-union has been described in patients under 5 years. ${ }^{18)}$ In contrast, the rate of non-union in conservatively treated adult patients is reported to be between $22 \%$ and $63 \% .^{2,4,7,12)}$ The long-term outcome after surgical treatment of pediatric odontoid fractures is still unknown, but there have been no growth disturbances in any of the 24 reported cases (one surgical fusion and 23 conservatively managed cases). ${ }^{14}$

We suggest that the first choice for management of odontoid fracture in an infant is conservative. However, non-union can occur even if adequate immobilization is maintained. Furthermore, it is difficult to confirm whether union has occurred in patients aged from 3 to 6 years. Definite union in our patient could not be demonstrated by cervical radiography following 3-month extracorporeal fixation with a halo brace. Surgical treatment for odontoid fractures has been reported in four children under the age of 7 years (Table 1). ${ }^{2,5,10,11)}$ Posterior fusion is the preferred procedure, and $\mathrm{C}-1$ to $\mathrm{C}-2 \mathrm{fu}-$ sion decreases axial rotation of the head by $50 \% .{ }^{17}{ }^{7}$ There were no complications after surgery in up to 5 years of follow-up. Anderson and D'Alonzo ${ }^{2)} \mathrm{de}-$ scribed a 3-year-old child with a displaced odontoid

Table 1 Summary of surgically managed odontoid fractures in children $(<7$ years old)

\begin{tabular}{|c|c|c|c|c|}
\hline Author (Year) & Age & Surgical procedure & $\begin{array}{l}\text { Follow-up } \\
\text { period }\end{array}$ & Result/Comment \\
\hline Price $(1960)^{11)}$ & 4 yrs & $\begin{array}{l}\mathrm{C} 1-2 \text { wiring and fusion with } \\
\text { autologous tibial bone graft }\end{array}$ & ND & $\begin{array}{l}\text { stabilized/deformity recurred } \\
\text { after removal of a plaster } \\
\text { jacket }\end{array}$ \\
\hline Hubbard $(1974)^{10)}$ & $2 \mathrm{yrs}$ & posterior fusion & $5 \mathrm{yrs}$ & $\begin{array}{l}\text { united } / \text { neck pain, functional } \\
\text { loss of neck rotation }\end{array}$ \\
\hline $\begin{array}{c}\text { Anderson and D'Alonzo } \\
(1974)^{2)}\end{array}$ & $3 \mathrm{yrs}$ & $\begin{array}{l}\mathrm{Cl}-2 \text { wiring and fusion with } \\
\text { bone-bank bone }\end{array}$ & ND & $\begin{array}{l}\text { united/bone-bank bone was } \\
\text { rapidly resorbed with wire } \\
\text { breakage }\end{array}$ \\
\hline $\begin{array}{l}\text { Diekema and Allen } \\
(1988)^{5)}\end{array}$ & $10 \mathrm{mos}$ & C1-2 fusion? & ND & no neurological sequelae \\
\hline Present case & $2 \mathrm{yrs}$ & $\begin{array}{l}\mathrm{C} 1-2 \text { wiring and fusion with } \\
\text { autologous iliac bone graft }\end{array}$ & 2 yrs & united/bone graft was absorbed \\
\hline
\end{tabular}

ND: not described. 
fracture treated by primary posterior wiring and fusion. Union of the odontoid process to the C-2 body was accomplished, despite absorption of the bone graft. Fusion of an odontoid fracture in adults usually takes 3-4 months, ${ }^{6}$ and in children takes 7-20 weeks with conservative therapy. ${ }^{4,8,9)}$ In our case, union was obtained at 4 months after the operation. Theoretically, there should be no difference between conservative and surgical therapy in the time taken for union if adequate immobilization can be obtained. Posterior fusion is the surgical procedure of choice as it is less invasive than anterior procedures and generally reliable. ${ }^{15,16)}$ We recommend early posterior fusion for odontoid fractures in children if non-operative methods fail to provide adequate immobilization of the slipped odontoid process.

\section{References}

1) Amyes EW, Anderson FM: Fracture of the odontoid process. Report of sixty-three cases. Arch Surg 72: 377-393, 1956

2) Anderson LD, D'Alonzo RT: Fractures of the odontoid process of the axis. J Bone Joint Surg Am 56: 1663-1674, 1974

3) Bailey DK: The normal cervical spine in infants and children. Radiology 59: 712-719, 1952

4) Blockey NJ, Purser DW: Fractures of the odontoid process of the axis. J Bone Joint Surg Br 38: 794-817, 1956

5) Diekema DS, Allen DB: Odontoid fracture in a child occupying a child restraint seat. Pediatrics 82: 117119,1988

6) Dunn ME, Seljeskog EL: Experience in the management of odontoid process injuries: An analysis of 128 cases. Neurosurgery 18: 306-310, 1986

7) Ekong CEU, Schwartz ML, Tator CH, Rowed DW, Edmonds VE: Odontoid fracture: Management with early mobilization using the halo device. Neurosurgery 9: 631-637, 1981

8) Ewald FC: Fracture of the odontoid process in a seventeen-month-old infant treated with a halo. A case report and discussion of the injury under the age of three. J Bone Joint Surg Am 53: 1636-1640, 1971

9) Hamilton AR: Injuries of the atlanto-axial joint. $J$ Bone Joint Surg Br 33: 434-435, 1951

10) Hubbard DD: Injuries of the spine in children and adolescents. Clin Orthop 100: 56-65, 1974

11) Price E: Fractured odontoid process with anterior dislocation. $J$ Bone Joint Surg Br 42: 410, 1960 (abstract)

12) Ryan MD, Taylor TKF: Odontoid fractures. A rational approach to treatment. J Bone Joint Surg Br 64: 416-421, 1982

13) Savader SJ, Martinez C, Murtagh FR: Odontoid fracture in a nine-month-old infant. Surg Neurol 24: 529_ 532,1985

14) Sherk HH, Nicholson JT, Chung SMK: Fractures of the odontoid process in young children. $J$ Bone Joint Surg $A m$ 60: 921-924, 1978

15) Vining DJ, Benzel EC, Orrison W: Childhood odontoid fractures evaluated with computerized tomography: Case report. $J$ Neurosurg 77: 795-798, 1992

16) Walters BC: Cranial bone grafts for use in posterior fixation of the cervical spine. Technical note. $J \mathrm{Neu}-$ rosurg 79: 286-288, 1993

17) Wilberger JEJ: Spinal Cord Injuries in Children. New York, Futura, 1986, p 14

18) Wilberger JEJ: Spinal Cord Injuries in Children. New York, Futura, 1986, pp 79-82

Address reprint requests to: K. Uemura, M.D., Department of Neurosurgery, Institute of Clinical Medicine, University of Tsukuba, 1-1-1 Tennoudai, Tsukuba, Ibaraki 305, Japan. 